\title{
INDETERMINACY, BUSINESS CYCLES, AND MODEST INCREASING RETURNS TO SCALE
}

\author{
Mark WEDER*
}

July 1, 1997

\begin{abstract}
In this paper a dynamic model of monopolistic competition with entry and exit has been presented and examined. It is shown that the model displays indeterminacy at modest degrees of increasing returns in cases where the market power in the consumption goods market and in the investment goods market differs. Furthermore, the model is quite successful in replicating major U.S. business cycle facts. In contrast to existing Real Business Cycle models, the animal spirits model contains a strong endogenous propagation mechanism.
\end{abstract}

\section{Introduction}

The question whether or not business cycles are generated by self-fulfilling beliefs is perhaps as old as the study of the business cycle itself. Until recently the notion of extrinsic uncertainty had never appeared in fully formulated

* Keywords: Sunspots, technology shocks, economic fluctuations.

Journal of Economic Literature Classification: E32.

Humboldt University Berlin, Department of Economics, Spandauer Str. 1, 10178 Berlin, Germany, weder@wiwi.hu-berlin.de.

I am indebted to Michael Burda, Dalia Marin, Ken Matheny, Martin Moryson and participants of the 1996 Meeting of the European Economic Association for valuable comments. All remaining errors are mine. 
Indeterminacy, Business Cycles and Modest Increasing Returns to Scale 2

models in modern macroeconomics. This notion used to be viewed as a theoretical curiosity outside the scope of equilibrium models. Yet, as recent developments in economic theory evince, the presence of a multiplicity of equilibria may not be fully unrealistic. Small departures from the world of Arrow-Debreu may yield very complex consequences. According to Azariadis

"[Multiple equilibria] are here to stay as irreducible properties of completely specified models of sequential economies" [Azariadis, 1992, 3].

The occurrence of more than one equilibrium raises an important question: Which equilibrium will be selected? One possible way to coordinate future outcomes may be the notion of Keynes' animal spirits: volatile optimistic or pessimistic expectations which ultimately become self-fulfilling. Business cycle fluctuations are at least in part due to endogenous factors.

Recently great strides were made in introducing the concept of animal spirits into a well defined equilibrium business cycle theory by Farmer and Guo (1995) as well as by Gali (1994). ${ }^{1}$ These models have one specific feature in common: the calibrated versions of their respective models possess a continuum of rational expectation solutions which all converge to the steady state. Recent empirical work, especially that conducted by Basu and Fernald, questions the assertion of these models to be realistic theories of the business cycle, however. Though data for U.S. industry points to the presence of scale economies and market power, the extent thereof seems to be rather modest and, more importantly, too low to give most existing models of indeterminacy a sound foundation as realistic models of the business cycle. This problem has led researchers to pursue alternative structures where indeterminacy can arise at lower scale economies. Benhabib and Farmer (1996) and Weder (1996), for example, use two-sector optimal growth models. This strategy allows the necessary degree of increasing returns to be reduced dramatically.

The underlying structure of the model in this paper, however, is based on an one-sector growth model of monopolistic competition in general equilibrium. It is similar to the model that is presented by Chatterjee and Cooper (1993). The distinctive feature of their model is that firms can practice price

\footnotetext{
${ }^{1}$ The Farmer and Guo paper originates from a growth model promoted by Benhabib and Farmer (1995). For a recent survey of the literature on indeterminacy see Benhabib and Farmer (1997).
} 
Indeterminacy, Business Cycles and Modest Increasing Returns to Scale 3

discrimination on the prospective use of the products, namely, for investment or consumption purposes. Chatterjee and Cooper's (1993) model is of regular form except for some unrealistic parameter constellations. It is driven by fundamental shocks only.

It will be demonstated in this paper that through rather minor alterations of their model, which center on the functional form of the production function, I am able to generate indeterminacy at modest increasing returns to scale. In addition the cyclical properties of the model I construct are similar to those found in data. In particular, the model possesses a strong internal propagation mechanism which generates highly persistent time series. This persistence arises without the help of highly autocorrelated forcing variables. $^{2}$

Perhaps most closely related to the present work is that by Gali (1994). He too constructs a model that has stationary sunspot equilibria in the presence of a sufficient difference in the rate of substitution between goods in consumption and investment. As a result of this asymmetry, a monopolistic firm faces a variable demand elasticity depending on the composition of aggregate demand. If the difference of the markups is large enough, fluctuations arise as a consequence of self-fulfilling revisions of expectations. Gali (1994) assumes, however, that firms are not able to price discriminate between investment and consumption goods markets. Chatterjee and Cooper (1993) in turn allow this price discrimination yet they are not able to show indeterminacy in realistic parameter ranges. Devereux, Head and Lapham (1996) is similar to Chatterjee and Cooper (1993) since they also consider entry and exit of monopolistic firms.

The remainder of this paper is organized as follows. Section 2 presents the model. The equilibrium dynamics are discussed in section 3 . This is followed by the calibration of the model in section 4 . In section 5 parameter constellations at which indeterminacy is possible will be established and the model's business cycle characteristics will be computed in section 6 . Section 7 concludes the paper.

\footnotetext{
${ }^{2}$ See Cogley and Nason (1995) for related problems that are present in most Real Business Cycles models.
} 
Indeterminacy, Business Cycles and Modest Increasing Returns to Scale 4

\section{The model}

This section introduces the theoretical model.

\subsection{The household}

I will assume that the economy consists of one representative agent with lifetime utility

$$
E\left[\sum_{t=0}^{\infty} \beta^{t} U\left(C_{t}, L_{t}\right) \mid \mathcal{I}_{0}\right]
$$

where $C_{t}$ is consumption, $L_{t}$ labor and $\beta$ the discount factor. $\mathcal{I}_{0}$ is the set of information that is available to the household at 0 . Households are endowed with one unit of time which they can either use for work or leisure $l_{t}$ :

$$
1=L_{t}+\mathrm{l}_{\mathrm{t}}
$$

A specific functional form for instantaneous utility is assumed:

$$
U\left(C_{t}, L_{t}\right)=\log C_{t}+\frac{B}{1+\chi}\left(1-L_{t}\right)^{1+\chi}
$$

where $B$ and $\chi$ are constants. Consumption of the households is defined by a CES-aggregator over all differentiated goods available:

$$
C_{t}=\left(\int_{0}^{N_{t}} C_{j, t}^{v} d j\right)^{1 / v} .
$$

That is, $C_{t}$ is a function of the level of consumption of an assembled variety of $N_{t}$ differentiated goods $C_{j, t} .0<v \leq 1$ holds. Each of these goods enters the aggregator symmetrically. For the case $v<1$, the goods are imperfect substitutes which will be the source of market power in the model.

Analogously to the consumption goods, an aggegator for the investment good $I_{t}$ is defined. Again it is a CES-function of the purchases of the differentiated products:

$$
I_{t}=\left(\int_{0}^{N_{t}} I_{j, t}^{\theta} d j\right)^{1 / \theta}
$$


Indeterminacy, Business Cycles and Modest Increasing Returns to Scale 5

where the parameter $\theta$ has the analog interpretation as $v$ and $0<\theta \leq 1$ holds again. As Gali (1994) notes, an a priori reason for the equality of $\theta$ and $v$ does not exist. The substitutability of the two goods originates from two unrelated sources.

The consumer's capital holdings evolve as

$$
K_{t+1}=(1-\delta) K_{t}+I_{t}
$$

$K_{t}$ denotes the stock of capital. $0 \leq \delta \leq 1$ is the rate of depreciation. The period-by-period budget constraint of the household is given by

$$
\int_{0}^{N_{t}} p_{c, j, t} C_{j, t} d j+\int_{0}^{N_{t}} p_{i, j, t} I_{j, t} d j=w_{t} L_{t}+q_{t} K_{t}+\Pi_{t} .
$$

Here $p_{c, j, t}$ is the price of the consumption $\operatorname{good} j$ and $p_{i, j, t}$ the price for the investment good $j .{ }^{3}$ Furthermore, the household receives profit income from all $N_{t}$ existing firms, $\Pi_{t}$. Households own the stock of capital and rent it out to the firms at the rental price $q_{t} . w_{t}$ is the wage rate. Both prices are taken as given for the households as factor markets are assumed to be perfectly competitive.

As is well known for this class of models, the maximization can be conducted as a two stage procedure: first the household considers how much of the composite goods $C_{t}$ and $I_{t}$ to demand as a function of prices (as well as how much labor to supply). Then the household considers how much to demand of each intermediate good given prices and the total expenditures. I will start with determining the individual demands given total expenditures on investment and consumption goods.

The conditional demand for $C_{j, t}$ can be derived as

$$
C_{j, t}=\left(\frac{p_{c, j, t}}{p_{c, t}}\right)^{\frac{1}{v-1}} C_{t} N_{t}^{-1 / v}
$$

which has, as can be seen, a constant price elasticity.

$$
p_{c, t}=\left(\frac{1}{N_{t}} \int_{0}^{N_{t}} p_{c, j, t}^{\frac{v}{v-1}} d j\right)^{\frac{v-1}{v}}
$$

\footnotetext{
${ }^{3}$ Note that these prices may differ since firms are allowed to price discriminate perfectly on the respective markets (see below).
} 
Indeterminacy, Business Cycles and Modest Increasing Returns to Scale 6

is the exact price index for the consumption goods. The same can be conducted for the investment goods. The conditional demand for $I_{j, t}$ becomes

$$
I_{j, t}=\left(\frac{p_{i, j, t}}{p_{i, t}}\right)^{\frac{1}{\theta-1}} I_{t} N_{t}^{-1 / \theta}
$$

with the price index

$$
p_{i, t}=\left(\frac{1}{N_{t}} \int_{0}^{N_{t}} p_{i, j, t}^{\frac{\theta}{\theta-1}} d j\right)^{\frac{\theta-1}{\theta}} .
$$

The second stage of the household's maximization will be considered next. I will assume symmetric equilibrium to derive the intertemporal optimality conditions. ${ }^{4}$ For convenience I will use the consumption good as the numeraire and denote the price for the investment goods in symmetric equilibrium by $p_{t}$. The period-by-period budget constraint becomes

$$
q_{t} K_{t}+w_{t} L_{t}+\Pi_{t} \geq C_{t} N_{t}^{\frac{v-1}{v}}-\left(K_{t+1}-(1-\delta) K_{t}\right) p_{t} N_{t}^{\frac{\theta-1}{\theta}}
$$

This equation shows that the household's value for the two aggregate goods $C_{t}$ and $I_{t}$ depends also on the number of available products. It is captured in the budget constraint by the terms $N_{t}^{\frac{v-1}{v}}$ and $N_{t}^{\frac{\theta-1}{\theta}}$ respectively. Differentiating these terms with respect to $N_{t}$ shows that the terms are decreasing in the number of suppliers as long as $v<1$ and $\theta<1$. This is another way of visualizing the concept of increasing returns to specialization.

To solve the household's intertemporal problem, the Lagrangian is defined as

$$
\begin{gathered}
\mathcal{L}=E\left[\sum _ { t = 0 } ^ { \infty } \beta ^ { t } \left(\log C_{t}+\frac{B}{1+\chi}\left(1-L_{t}\right)^{1+\chi}\right.\right. \\
\left.\left.+\lambda_{t}\left[q_{t} K_{t}+w_{t} L_{t}+\Pi_{t}-C_{t} N_{t}^{\frac{v-1}{v}}-\left(K_{t+1}-(1-\delta) K_{t}\right) p_{t} N_{t}^{\frac{\theta-1}{\theta}}\right]\right) \mid \mathcal{I}_{0}\right]
\end{gathered}
$$

Here $\lambda_{t}$ is the current value Lagrange multiplier associated with the household's resource constraint. The household solves (10) by choosing a sequence $\left\{C_{t}, L_{t}, K_{t+1}\right\}_{t=0}^{\infty}$ subject to a given $K_{0}$. The sequence of future states of technology $Z_{t}$ is not completely known at $t=0$. It is assumed that agents

\footnotetext{
${ }^{4}$ Symmetric equilibrium implies that each firm charges the same price $(\mathrm{s})$ for their product. The equilibrium will be formally derived in the next subsection.
} 
Indeterminacy, Business Cycles and Modest Increasing Returns to Scale 7

form rational expectations over these variables. The first order conditions can be written as

$$
\begin{gathered}
\frac{1}{C_{t}}-N_{t}^{\frac{v-1}{v}} \lambda_{t}=0 \\
B\left(1-L_{t}\right)^{\chi}-\lambda_{t} w_{t}=0 \\
\beta E\left[\lambda_{t+1}\left(q_{t+1}+(1-\delta) p_{t+1} N_{t+1}^{\frac{\theta-1}{\theta}}\right) \mid \mathcal{I}_{t}\right]-\lambda_{t} p_{t} N_{t}^{\frac{\theta-1}{\theta}}=0
\end{gathered}
$$

plus the household's budget constraint and the usual transversality condition. (11) and (12) describe the households consumption-leisure trade off and (13) is the intertemporal optimality condition.

\subsection{The firms}

There are $N_{t}$ monopolistic competitive firms supplying their good $j$ every period $t . N_{t}$ must not necessarily be constant, however. In particular, endogenous entry and exit of firms will be allowed. This process is modelled in the simplest possible fashion: purely static decision making is considered. That is, each firm decides to enter the economy (or to stay out of the market) every period: an active firm observes that its profit opportunities exceed its overhead costs. However, since free entry and exit is assumed, any profits are instantaneously dissipated. Overhead costs are 'lost in space', that is, they are not associated with any (labor) income. Each firm $j$ solves

$$
\max \Pi_{j, t}=p_{c, j, t} Y_{c, j, t}+p_{i, j, t} Y_{i, j, t}-w_{t} L_{j, t}-q_{t} K_{j, t}
$$

subject to the production function

$$
Y_{j, t}=Y_{c, j, t}+Y_{i, j, t}=Z_{t}\left(K_{j, t}^{\alpha} L_{j, t}^{1-\alpha}\right)^{\gamma}-\phi
$$

and to the (given) demand functions. Here, $Y_{c, j, t}\left(Y_{i, j, t}\right)$ is the amount of output to be sold as a consumption (investment) good. $K_{j, t}$ and $L_{j, t}$ are capital and labor input of firm $j$ at $t . p_{c, j, t}$ and $p_{i, j, t}$ are the prices of good $j$ if sold as a consumption or investment good. By the assumption of possible price discrimination, these prices need not be equal. $\phi$ is an overhead cost 
Indeterminacy, Business Cycles and Modest Increasing Returns to Scale 8

component when operating the firm. $Z_{t}$ is the state of technology which evolves as

$$
\log Z_{t+1}=\rho_{z} \log Z_{t}+\left(1-\rho_{z}\right) \log Z+z_{t+1}
$$

The sequence $\left\{z_{t}\right\}_{t=0}^{\infty}$ is white noise and $0<\rho_{z}<1$. The inverse demands for the goods of each firm are given by

$$
p_{c, j, t}=\left(\frac{Y_{c, j, t} N_{t}^{1 / v}}{C_{t}}\right)^{v-1} p_{c, t}
$$

and

$$
p_{i, j, t}=\left(\frac{Y_{i, j, t} N_{t}^{1 / \theta}}{I_{t}}\right)^{\theta-1} p_{i, t}
$$

if it is used as a consumption good or an investment good respectively. If $\theta=v=1$, no producer will be able to exploit market power. The cost function of firm $j$ is given by

$$
\mathbf{C}\left(w_{t}, q_{t}, Y_{j, t}\right)=A q_{t}^{\alpha} w_{t}^{1-\alpha}\left(\frac{Y_{j, t}+\phi}{Z_{t}}\right)^{\frac{1}{\gamma}} .
$$

The constant $A$ is defined as $A \equiv\left(\left(\frac{\alpha}{1-\alpha}\right)^{1-\alpha}+\left(\frac{\alpha}{1-\alpha}\right)^{-\alpha}\right)$. Given the constant price elasticity of demand, profit maximization requires that

$$
p_{c, j, t}=\frac{1}{v} \frac{\partial \mathbf{C}\left(q_{t}, w_{t}, Y_{j, t}\right)}{\partial Y_{j, t}}=\frac{1}{v} \frac{1}{\gamma Z_{t}} A q_{t}^{\alpha} w_{t}^{1-\alpha}\left(\frac{Y_{j, t}+\phi}{Z_{t}}\right)^{\frac{1}{\gamma}-1}
$$

and

$$
p_{i, j, t}=\frac{1}{\theta} \frac{\partial \mathbf{C}\left(q_{t}, w_{t}, Y_{j, t}\right)}{\partial Y_{j, t}}=\frac{1}{\theta} \frac{1}{\gamma Z_{t}} A q_{t}^{\alpha} w_{t}^{1-\alpha}\left(\frac{Y_{j, t}+\phi}{Z_{t}}\right)^{\frac{1}{\gamma}-1}
$$

hold. These are the standard pricing rules for monopoly pricing as a markup over marginal unit costs. That is, the markup is $1 / v$ and $1 / \theta$ respectively. Note that marginal costs are decreasing for $\gamma>1$ and increasing for $\gamma<1$.

Implicitly assumed here is that arbitrage is not possible. For example, goods that are sold as consumption goods cannot be transformed into investment goods. This can be defended as follows. The only case that will 
Indeterminacy, Business Cycles and Modest Increasing Returns to Scale 9

be considered is that of a lower price for consumption goods. Therefore, it would not make sense to the household to buy good $j$ on the investment market and use it as a consumption good. However, the opposite would be advantageous. This arbitrage could be ruled out, however, if one imposes some form of immediate (and full) depreciation of the good. In addition it must also be assumed that depreciation does not take effect when the good is (immediately) welded together with the other consumption goods according to 'technology' (4). This is analogous to the assumption of extremely high conversion costs.

The determination of the market participation will now be considered. At every period in time the number of active firms is determined by the zero profit condition

$$
p_{c, j, t} Y_{c, j, t}+p_{i, j, t} Y_{i, j, t}=A q_{t}^{\alpha} w_{t}^{1-\alpha}\left(\frac{Y_{j, t}+\phi}{Z_{t}}\right)^{\frac{1}{\gamma}} .
$$

Equations (19) and (20) yield

$$
\frac{p_{c, j, t}}{v}=\frac{p_{i, j, t}}{\theta} .
$$

Inserting the optimal pricing rules into equation (21) yields

$$
\frac{1}{v} Y_{c, j, t}+\frac{1}{\theta} Y_{i, j, t}=\gamma Z_{t}\left(K_{j, t}^{\alpha} L_{j, t}^{1-\alpha}\right)^{\gamma} .
$$

Without loss of generality, I use the consumption good as the numeraire (in symmetric equilibrium). This implies that the price for the investment goods becomes

$$
p_{i, j, t}=p_{t}=\frac{v}{\theta} .
$$

In symmetric equilibria (22) can be rewritten in terms of aggregate variables in the form of

$$
\frac{1}{v} \frac{C_{t}}{N_{t}^{1 / v}}+\frac{1}{\theta} \frac{I_{t}}{N_{t}^{1 / \theta}}=\gamma Z_{t}\left(K_{t}^{\alpha} L_{t}^{1-\alpha} N_{t}^{-1}\right)^{\gamma} .
$$

This equation can be combined with the firms' technology constraint to yield the equilibrium number of active firms implicitly as

$$
\left(\frac{1}{v}-\frac{1}{\theta}\right) \frac{C_{t}}{N_{t}^{1 / v}}=\left(\gamma-\frac{1}{\theta}\right) Z_{t}\left(K_{t}^{\alpha} L_{t}^{1-\alpha} N_{t}^{-1}\right)^{\gamma}+\frac{1}{\theta} \phi
$$


Indeterminacy, Business Cycles and Modest Increasing Returns to Scale 10

Equation (26) is a version of the zero profit condition in symmetric equilibrium. In the special case of $\theta=v$, the first term on the left hand side drops and the model's zero profit condition would collapse to the form present in Devereux, Head and Lapham (1996). However, it will become clear in the following section that this assumption of symmetry would rule out the conditions for indeterminacy at modest degrees of scale economies.

Combining the optimal pricing rule with the conditional demand for labor, it is posssible to derive the wage rate as

$$
w_{t}=v \gamma(1-\alpha) Z_{t}\left(K_{t}^{\alpha} L_{t}^{1-\alpha}\right)^{\gamma} L_{t}^{-1} N_{t}^{1-\gamma} .
$$

Analogously the rental rate of capital is given as

$$
q_{t}=v \gamma \alpha Z_{t}\left(K_{t}^{\alpha} L_{t}^{1-\alpha}\right)^{\gamma} K_{t}^{-1} N_{t}^{1-\gamma}
$$

Note that this simple aggregation of the conditional demands does not yet yield the actual rental prices. These demands must be combined with the equilibrium value for $N_{t}$ as given by the zero profit condition. A closed form solution for $N_{t}$, as can be seen from (26), does not exist as long as $\theta \neq v$. However, this problem can be circumvented by the solution mechanism which is described below. The measure of overall aggregate output $Y_{t}$ is defined as

$$
Y_{t}=N_{t} y_{t}
$$

Finally, the variable sales $S_{t}$ is defined as

$$
S_{t}=v \gamma Z_{t} K_{t}^{\alpha \gamma} L_{t}^{(1-\alpha) \gamma} N_{t}^{1-\gamma}
$$

which is simply the sum of capital and labor income.

\section{The equilibrium dynamics}

This section delivers the equilibrium dynamics around the economy's steady state.

\subsection{The steady state}

Using the zero profit condition for the firms and the pricing rule, the derivation of the expression for the steady state number of firms as a function of 
Indeterminacy, Business Cycles and Modest Increasing Returns to Scale 11

the model parameters only is given by

$$
\left.N=\left[(\theta-v) C / S-\theta+\frac{1}{\gamma}\right)\right] /(v \phi / S)
$$

where omission of the time index implies steady state values. $S$ is the steady state aggregate sales of the firms. $C S \equiv C N^{\frac{v-1}{v}} / S$, the share of consumption expenditures.

It can be shown by implicit differentiation that

$$
\frac{\partial \log N}{\partial \log (\phi / S)}<0, \quad \frac{\partial \log N}{\partial \log \gamma}<0, \quad \frac{\partial \log N}{\partial \log v}<0, \quad \frac{\partial \log N}{\partial \log \theta}<0,
$$

and

$$
\operatorname{sign}\left[\frac{\partial \log N}{\partial \log (C S)}\right]=\operatorname{sign}\left[\frac{\theta}{v}-1\right]
$$

Therefore a rise in the respective market power measures $1 / v$ and $1 / \theta$ lowers the steady state number of firms since the profit margin decreases. Also, the composition of demand, CS, influences the number of firms. In particular, if the market power is greater in the consumption sector, that is $v<\theta$, an increase in $C S$ raises $N .^{5}$ The remaining steady state equations are given by

$$
\delta K=I
$$

and

$$
\beta\left(q+(1-\delta) \frac{v}{\theta} N^{\frac{\theta-1}{\theta}}\right)=\frac{v}{\theta} N^{\frac{\theta-1}{\theta}}
$$

These last two equations are standard in Real Business Cycle models.

\subsection{The solution mechanism}

The following section describes the dynamics of the economy near its steady state. Since the Second Welfare Theorem does not apply because of market power, the dynamics cannot be derived by means of the social planner

\footnotetext{
${ }^{5}$ Note that for $\theta=v$ the production function must exhibit increasing returns in variable production to achieve a strictly positive measure of firms, that is $1>\gamma \theta$. A rise of the overhead costs results in a decrease of the number of firms as expected.
} 
Indeterminacy, Business Cycles and Modest Increasing Returns to Scale 12

problem. I use the solution method firstly described by King, Plosser and Rebelo (1988).

The linearized model boils down to the following matrix difference equation:

$$
\left[\begin{array}{c}
E\left[\hat{\lambda}_{t+1} \mid \mathcal{I}_{t}\right] \\
\hat{K}_{t+1} \\
E\left[\hat{Z}_{t+1} \mid \mathcal{I}_{t}\right]
\end{array}\right]=J\left[\begin{array}{c}
\hat{\lambda}_{t} \\
\hat{K}_{t} \\
\hat{Z}_{t}
\end{array}\right]
$$

where $J$ is $3 \times 3$. The system contains one predetermined endogenous variable (the stock of capital), one predetermined exogenous variable (the state of technology) and one endogenous nonpredetermined variable (the shadow value of wealth). In the standard rational expectations case with an unique equilibrium, the model shows the standard saddle path behavior only if one eigenvalue is strictly outside the unit circle. This model property must be checked because of its imperfect market structure. Since the First Welfare Theorem no longer applies, the equilibrium must no longer be unique. Furthermore, the possibility of a multiplicity of stationary rational expectations paths exists, giving rise to sunspot equilibria. However, before that case can be examined, the model must first be calibrated.

\section{Calibration}

Parameter value determination is in accord with the Real Business Cycle tradition: steady state values of the model will be matched with estimates of average growth rates and great ratios. First a baseline model structure will be defined.

Consistent with McGrattan (1994) I will set $\delta$ equal to 0.023 on a quarterly basis. $\alpha$ will be set to 0.30 . Since the production function is assumed to be Cobb-Douglas, the parameter $\alpha$ equals the capital share. The capital share of GNP net of housing was about 30 percent for the U.S. 1954 to 1989 period. It is assumed that $C S$ will be 0.75 , which is the same value as in Schmitt-Grohe (1995). Furthermore the quarterly discount factor $\beta$ will be set to 0.995 (see Cechetti et al., 1993).

For the case $\chi=0$, the model's labor market corresponds to the Hansen (1985) and Rogerson (1987) indivisible labor market formulation. As in Hansen (1985), the share of time endowment that the representative household 
Indeterminacy, Business Cycles and Modest Increasing Returns to Scale 13

spends on market activities is set to $L=1 / 3$. This assumption made on $L, \chi=-1 / 2$ corresponds to the King, Plosser and Rebelo (1988) baseline calibration for the labor supply elasticity of four.

The remaining parameters are $v, \theta$ and $\gamma$. Basu and Fernald (1994) report estimates for increasing returns between 1.00 to 1.26. However, their preferred point estimate is 1.03. Market power as measured by markups over costs is reported by Morrison (1990) to be around 1.14. These values should act as a measure for realistic calibrations.

\section{$5 \quad$ Results}

This section will first evaluate the parameter space in which indeterminacy can arise. Second moments are derived in the latter part of the section.

\subsection{Eigenvalues}

The occurrence of indeterminacy will be analyzed in this subsection. As will be shown, this model characteristic depends on the range of increasing returns as well as on the relative market power in the two product markets. Indeterminacy is present in the model as long as both roots of the matrix $J$ are inside the unit circle. However, since the analytical solution of the matrix $J$ is a bette noire, a numerical procedure is considered here.

The set of the following variables is calibrated throughout this section as follows $C S=0.75, \delta=0.023$ and $\beta=0.995$. In light of Shea (1993), Burnside, Eichenbaum and Rebelo (1995) and others, the model must be checked to see if it is capable of generating indeterminacy without the assumption of decreasing marginal costs. First $\gamma=1.00$ will be set, which implies constant marginal costs.

Table 1 considers alternative (but identical) values for $v$ and $\theta$. Basu and Fernald (1994) as well as Morrison (1990) report markups of up to 1.30. Therefore $\theta$ and $v$ will be calibrated in this region. ${ }^{6}$

\footnotetext{
${ }^{6}$ The third eigenvalue of the matrix $J$, which is not reported in the following Tables, is the persistence parameter of the technology sequence $\rho_{z}$. Since technology is stationary in the model economy, $\rho_{z}$ is inside the unit circle. The markup is the inverse of $v$ and $\theta$. See the Appendix for a discussion.
} 
Indeterminacy, Business Cycles and Modest Increasing Returns to Scale 14

\begin{tabular}{|l|l|l|l|l|l|}
\hline \multicolumn{7}{|c|}{ Table 1: Roots of Model } \\
\hline \hline$v$ & $\theta$ & $\gamma$ & Root 1 & Root 2 & \\
\hline \hline 0.90 & 0.90 & 1.00 & 1.083 & 0.937 & saddlepath stable \\
\hline 0.80 & 0.80 & 1.00 & 1.122 & 0.934 & saddlepath stable \\
\hline 0.70 & 0.70 & 1.00 & 1.528 & 0.925 & saddlepath stable \\
\hline 0.65 & 0.65 & 1.00 & $0.903+0.779 \mathrm{i}$ & $0.903-0.779 \mathrm{i}$ & stable \\
\hline 0.60 & 0.60 & 1.00 & $0.932+0.050 \mathrm{i}$ & $0.932-0.050 \mathrm{i}$ & stable \\
\hline
\end{tabular}

The remaining variables are calibrated as follows: $\alpha=0.30, C S=0.75, \delta=0.023$ and $\beta=0.995$.

Table 1 shows that the roots split around unity unless the markup (and implicitly the returns to scale) becomes very large. ${ }^{7}$ The value of $v=\theta=$ 0.65 corresponds to scale economies of 1.54, which is within Baxter and King's (1991) range. ${ }^{8}$ Nevertheless, indeterminacy cannot arise with symmetrical markups at modest increasing returns. Table 2 considers heterogenous degrees of market power. In particular, it is assumed that the investment demand is less elastic than consumption demand (holding $v$ at 0.95$).{ }^{9}$

\begin{tabular}{|l|l|l|l|l|l|}
\hline \multicolumn{7}{|c|}{ Table 2: Roots of Model } \\
\hline \hline$v$ & $\theta$ & $\gamma$ & Root 1 & Root 2 & \\
\hline \hline 0.95 & 0.90 & 1.00 & 1.099 & 0.927 & saddlepath stable \\
\hline 0.95 & 0.85 & 1.00 & 1.341 & 0.869 & saddlepath stable \\
\hline 0.95 & 0.825 & 1.00 & $0.949+0.139 \mathrm{i}$ & $0.949-0.139 \mathrm{i}$ & stable \\
\hline 0.95 & 0.80 & 1.00 & $0.979+0.083 \mathrm{i}$ & $0.979-0.083 \mathrm{i}$ & stable \\
\hline 0.95 & 0.75 & 1.00 & $0.989+0.053 \mathrm{i}$ & $0.989-0.053 \mathrm{i}$ & stable \\
\hline 0.95 & 0.70 & 1.00 & $0.993+0.040 \mathrm{i}$ & $0.993-0.040 \mathrm{i}$ & stable \\
\hline
\end{tabular}

The set of the remaining variables is calibrated as follows: $\alpha=0.30, C S=0.75$, $\delta=0.023$ and $\beta=0.995$.

\footnotetext{
${ }^{7}$ These Tables are to be read as follows: the leftmost column(s) depict alternative parameter spaces, the columns denoted by Roots 1 and 2 refer to the numerical eigenvalues of the matrices $J$. The rightmost column denotes the qualitative dynamics of the model, that is, if the parameter space is denoted to be stable, the model is indeterminate.

${ }^{8}$ Note that this minimum of returns to scale is about the same as that required by Benhabib and Farmer (1994). Unlike these authors, I did not have to assume decreasing marginal costs for this result.

${ }^{9}$ This pattern is indirectly supported by evidence given by Basu and Fernald (1996).
} 
Indeterminacy, Business Cycles and Modest Increasing Returns to Scale 15

The assumed asymmetry leads to indeterminacy. The preceeding Table shows that for small differences in the markup in the two output markets, the model can be indeterminate. In particular, it is required that the degree of market power in the investment market exceeds the respective degree in the market for consumption goods. The implied returns to scale are modest in this case. The average steady state markup of the firm will be defined as

$$
C S v^{-1}+(1-C S) \theta^{-1}
$$

This implies that for market powers $\theta=0.825$ and $v=0.95$, the returns to scale amount to $1.09 .^{10}$ This value is well within the range that is reported by Morrison (1990) as well as Basu and Fernald (1995). Furthermore, marginal costs must not decrease sharply unlike in related works.

It can be shown that the result is not restricted to the particular choice of parameters. To illuminate this, the market power parameter $v$ is set at 0.90 in Table 3.

\begin{tabular}{|l|l|l|l|l|l|}
\hline \multicolumn{9}{|c|}{ Table 3: Roots of Model } \\
\hline \hline$v$ & $\theta$ & $\gamma$ & Root 1 & Root 2 & \\
\hline \hline 0.90 & 0.85 & 1.00 & 1.118 & 0.926 & saddlepath stable \\
\hline 0.90 & 0.80 & 1.00 & 3.295 & 0.854 & saddlepath stable \\
\hline 0.90 & 0.775 & 1.00 & $0.947+0.109 \mathrm{i}$ & $0.949-0.109 \mathrm{i}$ & stable \\
\hline 0.90 & 0.75 & 1.00 & $0.974+0.077 \mathrm{i}$ & $0.974-0.077 \mathrm{i}$ & stable \\
\hline 0.90 & 0.70 & 1.00 & $0.987+0.051 \mathrm{i}$ & $0.987-0.051 \mathrm{i}$ & stable \\
\hline
\end{tabular}

The set of the remaining variables is calibrated as follows: $\alpha=0.30, C S=0.75$, $\delta=0.023$ and $\beta=0.995$.

The result here is similar to the one in Table 2. If the markups differ sufficiently, indeterminacy is possible. The next Table considers the reverse case of stronger market power in the consumption goods sector.

\footnotetext{
${ }^{10}$ See the Appendix for a discussion.
} 
Indeterminacy, Business Cycles and Modest Increasing Returns to Scale 16

\begin{tabular}{|l|l|l|l|l|l|}
\hline \multicolumn{5}{|c|}{ Table 4: Roots of Model } \\
\hline \hline$v$ & $\theta$ & $\gamma$ & Root 1 & Root 2 & \\
\hline \hline 0.80 & 0.95 & 1.00 & 1.071 & 0.942 & saddlepath stable \\
\hline 0.70 & 0.95 & 1.00 & 1.070 & 0.942 & saddlepath stable \\
\hline 0.80 & 0.95 & 1.00 & 1.069 & 0.943 & saddlepath stable \\
\hline 0.80 & 0.90 & 1.00 & 1.082 & 0.938 & saddlepath stable \\
\hline 0.70 & 0.90 & 1.00 & 1.082 & 0.938 & saddlepath stable \\
\hline 0.80 & 0.90 & 1.00 & 1.081 & 0.939 & saddlepath stable \\
\hline
\end{tabular}

The set of the remaining variables is calibrated as follows: $\alpha=0.30, C S=0.75$, $\delta=0.023$ and $\beta=0.995$.

The preceeding Table shows that in order for indeterminacy to arise, the degree of market power in the consumption market must not exceed the respective degree in the market for investment goods. ${ }^{11}$

The following Table demonstrates that the assumption on the labor supply elasticity is not of decisive importance for the occurrence of indeterminacy. However, the difference in market power must increase in comparison to the above considered case. This also implies that the returns to scale which are necessary to achieve the same result must increase. $\chi$ will be set to $-1 / 2$ in which the labor supply elasticity of the model equals elasticity of the baseline Real Business Cycle model as in King, Plosser and Rebelo (1988).

\begin{tabular}{|l|l|l|l|l|l|}
\hline \multicolumn{6}{|c|}{ Table 5: Roots of Model } \\
\hline \hline$v$ & $\theta$ & $\gamma$ & Root 1 & Root 2 & \\
\hline \hline 0.90 & 0.85 & 1.00 & 1.077 & 0.947 & saddlepath stable \\
\hline 0.90 & 0.80 & 1.00 & 1.111 & 0.938 & saddlepath stable \\
\hline 0.90 & 0.75 & 1.00 & 2.210 & 0.894 & saddlepath stable \\
\hline 0.90 & 0.70 & 1.00 & $0.973+0.069 \mathrm{i}$ & $0.973-0.069 \mathrm{i}$ & stable \\
\hline 0.90 & 0.65 & 1.00 & $0.984+0.046 \mathrm{i}$ & $0.984-0.046 \mathrm{i}$ & stable \\
\hline
\end{tabular}

The set of the remaining variables is calibrated as follows: $\chi=-1 / 2, \alpha=0.30$, $C S=0.75, \delta=0.023$ and $\beta=0.995$.

Indeterminacy may still arise with a lower labor supply elasticity yet the

\footnotetext{
${ }^{11}$ However, this result can be circumvented if $\gamma>1$.
} 
Indeterminacy, Business Cycles and Modest Increasing Returns to Scale 17

returns to scale that are needed to generate this case are higher. The model with $\chi=-1 / 2$ bifurcates into a completely stable one at returns to scale of 1.19. This value is still not far outside of what is considered empirically plausible.

Until this point it has been assumed that marginal costs are constant. The next exercise which is reported in Table 6 assumes $\gamma$ to be 1.10.

\begin{tabular}{|l|l|l|l|l|l|}
\hline \multicolumn{6}{|c|}{ Table 6: Roots of Model } \\
\hline \hline$v$ & $\theta$ & $\gamma$ & Root 1 & Root 2 & \\
\hline \hline 0.90 & 0.85 & 1.10 & 1.088 & 0.941 & saddlepath stable \\
\hline 0.90 & 0.80 & 1.10 & 1.391 & 0.889 & saddlepath stable \\
\hline 0.90 & 0.775 & 1.10 & $0.955+0.103 \mathrm{i}$ & $0.955-0.103 \mathrm{i}$ & stable \\
\hline 0.90 & 0.75 & 1.10 & $0.980+0.069 \mathrm{i}$ & $0.980-0.069 \mathrm{i}$ & stable \\
\hline 0.90 & 0.70 & 1.10 & $0.990+0.045 \mathrm{i}$ & $0.990-0.045 \mathrm{i}$ & stable \\
\hline
\end{tabular}

The set of the remaining variables is calibrated as follows: $\chi=-1 / 2, \alpha=0.30$, $C S=0.75, \delta=0.023$ and $\beta=0.995$.

The presence of decreasing marginal costs allows the minimum required sectoral markups to be reduced. Returns to scale of 1.16 are needed for indeterminacy to apply.

To summarize this section, the one-sector growth model that is presented displays indeterminacy at rather modest returns to scale. Multiplicity of rational expectations equilibria occurs at increasing returns to scale as low as 1.10. This can be seen as a significant innovation compared to several other models of indeterminacy. The model easily avoids empirical and theoretical criticism that has been directed at related work.

\subsection{Interpretation}

Intertemporal models of monopolistic competition generally have the potential of irregular, that is indeterminate, solutions. Since the Second Welfare Theorem does not apply, the equilibrium is no longer necessarily unique. Moreover, if the model possesses the above structure, economic fluctuations in response to random events that do not involve any change in the fundamentals may arise. It should be noted that it is not necessarily incorrect to form expectations in this manner. In a rational expectations equilibrium, 
Indeterminacy, Business Cycles and Modest Increasing Returns to Scale 18

it is correct to follow these animal spirits when all agents expect these to matter (as in Keynes' beauty contest).

The specific result of the present model requires an interpretation. The economic intuition is as follows: suppose that the representative agent expects future output to be high, this means that they also expect a large number of active firms in the economy. In the case of a booming economy, the returns to capital are high (given the scale economies and market participation). Thus, agents start to invest more in the present period. If the elasticity of investment demand is lower than the demand elasticity of consumption $(\theta<v)$, this again implies that at given prices revenues of every firm increase. More firms enter the economy to take advantage of these opportunities until profits are dissipated through enough entry. This again spreads the decreasing returns of the single inputs (the increasing returns to specialization effect) and thereby increases present output. Also, the increase in product variety shifts outwards the labor supply and leads to more accumulation, which in turn encourages even more entry in the present and future periods. This translates into a higher future capital stock and the expected boom is self-fulfilling. The endogenous variation of the product space is also responsible for the strong internal propagation mechanism in the model (see the following section).

\section{Second moments}

The presented model must be judged on how good it can replicate the variability of the different aggregate macroeconomic time series behavior.

\subsection{Population moments}

The following Tables report population moments for the U.S. economy. Log levels were detrended by computing deviations from a common estimated linear trend (see King, Plosser and Rebelo, 1988 for details). Table 7 reports the amplitudes of the fluctuations in aggregate variables in order to access their relative magnitudes. These are measured by the respective standard deviations of the variables output, consumption, investment, employment and the real wage. 
Indeterminacy, Business Cycles and Modest Increasing Returns to Scale 19

\begin{tabular}{|c|c|c|c|}
\hline \multicolumn{4}{|c|}{$\begin{array}{l}\text { Table 7: Sample Moments: U.S.A } \\
\text { 1948:I-1986:IV }\end{array}$} \\
\hline variable & $\overline{\sigma_{x} / \sigma_{S}}$ & $\overline{\overline{\sigma_{x, S}}}$ & $\overline{\mathrm{AC} 1}$ \\
\hline Output & 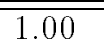 & 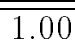 & 0.96 \\
\hline Consumption & 0.69 & 0.85 & 0.98 \\
\hline Investment & 1.35 & 0.60 & 0.93 \\
\hline Employment & 0.53 & 0.07 & 0.94 \\
\hline Real wage & 1.15 & 0.76 & 0.97 \\
\hline
\end{tabular}

$\sigma_{x} / \sigma_{S}$ denotes the relative standard deviation of variable $x$ with output. AC1 denotes the first order autocorrelation of the variable. $\sigma_{x, S}$ denotes the correlation of variable $x$ with output.Basic source of data: Quarterly data from National Income Accounts. The table is taken from King, Plosser and Rebelo (1988).

The well known business cycle fact that consumption fluctuates less than output, and that investment displays a greater volatility than output, can be observed. Table 7 also reports high autocorrelation coefficients for the same list of variables. Finally, it is shown that all variables considered are strongly procyclical with the exception of employment. ${ }^{12}$ We now return to the baseline animal spirits model in the following section.

Since business formation takes on an important role in the model, I shall thus present evidence of firms' entry and exit decision patterns over the business cycle. The procyclical behavior of net business formation is well documented for the U.S. economy (see for example Audretsch and Acs, 1991). The following Table reports the contemporaneous correlation of German GDP and three measures of firms' participation rate. A loglinear detrending procedure has been applied.

\begin{tabular}{|l|l|l|}
\hline \multicolumn{3}{|c|}{ Table 8 } \\
\hline \hline \multirow{2}{*}{ Variable } & \multicolumn{2}{|c|}{ correlation with GDP } \\
\cline { 2 - 3 } & LT & HP \\
\hline \hline Limited companies & 0.07 & 0.35 \\
\hline Stock companies & 0.55 & 0.60 \\
\hline Insolvencies & -0.68 & -0.79 \\
\hline
\end{tabular}

Log levels of each annual series were detrended by computing deviations from an estimated linear trend (LT) or Hodrick-Prescott trend (HP). The variables are the following.

\footnotetext{
${ }^{12}$ See King, Plosser and Rebelo (1988) for a discussion of the acyclicality of employment and the sensitivity of this result on the detrending method.
} 
Indeterminacy, Business Cycles and Modest Increasing Returns to Scale 20

Number of firms: limited companies (GmbHs), stock companies (AGs) and insolvencies. Basic Source of data: Statistisches Bundesamt.

The Table reports procyclical behavior for the number of firms in the German economy. Also, market exit (as measured by insolvency) appears to be present mainly at business cycle downturns. However, the number of limited companies seems not to be correlated with the cycle.

\subsection{Model moments}

The dynamical system (31) which is considered here has all roots inside the unit circle for the baseline calibration. For a given initial capital stock $\hat{K}_{0}$, $\left\{Z_{t}\right\}_{t=0}^{\infty}$ and an arbitrary (nonpredetermined) $\hat{\lambda}_{0}$, one can generate a sequence of probability distributions of the random variables $\left\{\hat{\lambda}_{t}, \hat{K}_{t}\right\}_{t=1}^{\infty}$ by adding another arbitrary random variable sequence $\left\{u_{t}\right\}_{t=1}^{\infty}$. This latter sequence of shocks represents beliefs of agents which act in the very same way as Keynes's animal spirits, as the driving force of the model economy by shocking $\hat{\lambda}_{t+1}$. In the present case, however, it is not necessary to simulate the model since it is possible to compute the moments of the model directly. Equation (31) can be written in the form of a first order vector autoregressive process

$$
s_{t+1} \equiv\left[\begin{array}{c}
\hat{\lambda}_{t+1} \\
\hat{K}_{t+1} \\
Z_{t+1}
\end{array}\right]=J\left[\begin{array}{c}
\hat{\lambda}_{t} \\
\hat{K}_{t} \\
Z_{t}
\end{array}\right]+\left[\begin{array}{c}
u_{t+1} \\
0 \\
z_{t+1}
\end{array}\right] \equiv J s_{t}+\epsilon_{t+1} .
$$

This equation describes the equilibrium laws of motion of the model. $e_{t+1}$ is a sequence of independent random variables drawn from a distribution with mean zero and constant variance.

\subsection{Model moments: results}

The following Tables report the second moments for the baseline model. In order to be able to extract the working mechanism of the model, several adaptions will be considered which are driven by technology shocks, animal spirits shocks or a combination thereof.

The first model version that is considered is described by the following list of parameter values. 
Indeterminacy, Business Cycles and Modest Increasing Returns to Scale 21

\begin{tabular}{|l|l|l|l|}
\hline \multicolumn{4}{|c|}{ Table 9: Model parameters } \\
\hline \hline$\chi$ & $v$ & $\theta$ & $\gamma$ \\
\hline \hline 0.00 & 0.90 & 0.75 & 1.00 \\
\hline
\end{tabular}

By assuming the parameters as in Table 9, the labor market corresponds to the indivisible labor concept by Hansen (1985). Marginal costs are constant and the returns to scale are only modest $(=1.17)$. With these parameter assumptions, the matrix $J$ has all three roots smaller than unity. This fact can be exploited in order to introduce animal spirits as a source for economic fluctuations. The model that is reported in Table 10 is driven by white noise animal spirits shocks only.

\begin{tabular}{|l|l|l|l|}
\hline \multicolumn{4}{|c|}{ Table 10: Moments } \\
\hline \hline variable & $\sigma_{x} / \sigma_{S}$ & $\sigma_{x, S}$ & AR1 \\
\hline \hline$S$ & 1.00 & 1.00 & 0.97 \\
\hline$C$ & 0.48 & 0.22 & 0.99 \\
\hline$C N^{\frac{v-1}{v}}$ & 0.52 & -0.20 & 0.97 \\
\hline$I$ & 5.23 & 0.95 & 0.95 \\
\hline$\frac{v}{\theta} I N^{\frac{\theta-1}{\theta}}$ & 4.58 & 0.94 & 0.95 \\
\hline$N$ & 1.95 & 0.27 & 0.95 \\
\hline$L$ & 1.22 & 0.94 & 0.97 \\
\hline$w$ & 0.52 & -0.20 & 0.99 \\
\hline
\end{tabular}

The economy is driven by white noise animal spirits shocks only. $S$ denotes aggregate expenditures, $C$ consumption, $I$ investment, $N$ number of active firms, $L$ labor input and $w$ labor productivity.

Table 10 reports that all variables possess the correct relative volatilities and are all highly autocorrelated. However, the procyclicality of consumption expenditures in data cannot be replicated in this version of the model. ${ }^{13} \mathrm{In}$ addition, productivity is countercyclical, which also conflicts with data. The next Table assumes the case $\gamma=1.10$.

\footnotetext{
${ }^{13}$ Note that a similar result of the wrong sign of crosscorrelations is also reported in Chatterjee and Cooper (1993). The reason behind the countercyclical expenditure pattern is the procyclical entry of firms. Consumption expenditures $\left(C_{t} N_{t}^{\frac{v-1}{v}}\right)$ decrease in the (procyclical) number of firms.
} 
Indeterminacy, Business Cycles and Modest Increasing Returns to Scale 22

\begin{tabular}{|l|l|l|l|}
\hline \multicolumn{4}{|c|}{ Table 11: Moments } \\
\hline \hline variable & $\sigma_{x} / \sigma_{S}$ & $\sigma_{x, S}$ & AR1 \\
\hline \hline$S$ & 1.00 & 1.00 & 0.99 \\
\hline$C$ & 0.75 & 0.59 & 0.99 \\
\hline$C N^{\frac{v-1}{v}}$ & 0.82 & 0.19 & 0.99 \\
\hline$I$ & 5.73 & 0.84 & 0.98 \\
\hline$\frac{v}{\theta} I N^{\frac{u-1}{\theta}}$ & 4.47 & 0.83 & 0.98 \\
\hline$N$ & 3.77 & 0.85 & 0.98 \\
\hline$L$ & 1.22 & 0.74 & 0.98 \\
\hline$w$ & 0.82 & 0.10 & 0.99 \\
\hline
\end{tabular}

The economy is driven by white noise animal spirits shocks only.

All variables are procyclical. Note in particular that consumption (as measured by $C_{t}$ and as consumption expenditures) is now positively correlated with output, even though the model is demand driven. As can also be seen in Table 11, the model is successful in replicating the relative volatility of the main macroeconomic variables. The standard deviation of investment exceeds the one of output and consumption. However, assuming indivisible labor in the present model has the effect that hours are too volatile.

The model is also very successful in reproducing strong autocorrelations. This is a compelling result, especially considering that the shock sequence was assumed to be i.i.d. Note that Farmer and Guo (1994) report a similar result for their animal spirits model. An important aspect of the model reported in Table 11 is the procyclical behavior of productivity. It is well known from Baxter and King (1991) and Chatterjee and Cooper (1993) that demand driven business cycle models which are based on the one-sector optimal growth model have problems generating this pattern unless returns to scale are sufficiently large. The present model is able to produce procyclical labor productivity without relying on overly strong returns to scale, however. Also, even for researchers who do not believe in sunspots, the present model offers an example which comprises a strong endogenous propagation mechanism.

Table 12 adds persistent technology shocks to the last model version $\left(\rho_{z}=\right.$ 0.974). Since no measure of the size of animal spirits shocks exists, it is simply assumed that the volatilities of both shocks are of equal size. Both shocks are uncorrelated with each other. 
Indeterminacy, Business Cycles and Modest Increasing Returns to Scale 23

\begin{tabular}{|l|l|l|l|}
\hline \multicolumn{4}{|c|}{ Table 12: Moments } \\
\hline \hline variable & $\sigma_{x} / \sigma_{S}$ & $\sigma_{x, S}$ & AR1 \\
\hline \hline$S$ & 1.00 & 1.00 & 0.99 \\
\hline$C$ & 0.77 & 0.70 & 1.00 \\
\hline$C N^{\frac{v-1}{v}}$ & 0.71 & 0.56 & 0.99 \\
\hline$I$ & 4.21 & 0.86 & 0.99 \\
\hline$\frac{v}{\theta} I N^{\frac{q-1}{\theta}}$ & 3.47 & 0.84 & 0.98 \\
\hline$N$ & 1.75 & 0.94 & 0.98 \\
\hline$L$ & 0.71 & 0.72 & 0.98 \\
\hline
\end{tabular}

The economy is driven by white noise animal spirits shocks and by highly persistent technology shocks. The variance of both shock sequences was equalized.

The model predicts the correct crosscorrelations and relative variabilities. However, the volatility of hours is still far too high. Therefore, the labor supply elasticity is reduced dramatically. By setting $\chi=-5$, the elasticity of labor supply is within the range of panel data studies as reported in Pencavel (1986).

\begin{tabular}{|l|l|l|l|}
\hline \multicolumn{4}{|c|}{ Table 13: Moments } \\
\hline \hline variable & $\sigma_{x} / \sigma_{S}$ & $\sigma_{x, S}$ & AR1 \\
\hline \hline$S$ & 1.00 & 1.00 & 0.99 \\
\hline$C$ & 1.34 & 0.90 & 1.00 \\
\hline$C N^{\frac{v-1}{v}}$ & 1.50 & 0.66 & 0.99 \\
\hline$I$ & 5.78 & 0.31 & 0.99 \\
\hline$\frac{v}{\theta} I N^{\frac{\theta-1}{\theta}}$ & 3.52 & 0.28 & 0.99 \\
\hline$N$ & 5.30 & 0.35 & 0.98 \\
\hline$L$ & 0.32 & 0.72 & 0.98 \\
\hline
\end{tabular}

The economy is driven by white noise animal spirits shocks and by highly persistent technology shocks. The standard deviation of both shock sequences was equalized. $\gamma=$ 1.125. The roots of the matrix $J$ are $0.981 \pm 0.058 \mathrm{i}$.

As expected, the volatility of hours is reduced to a realistic value. However, the consequence is that consumption expenditures are far too volatile.

To summarize, the model that is introduced in this paper can generate indeterminate equilibrium dynamics at modest returns to scale. The indeterminacy can be exploited in order to introduce extrinsic uncertainty into 
Indeterminacy, Business Cycles and Modest Increasing Returns to Scale 24

the model. The model is quite successful in replicating major business cycle facts as second moments as well as crosscorrelations even when driven by white noise animal spirits shocks. Of particular significance is the model's endogenous propagation mechanism. Even when the model is driven by white noise shocks, all variables are highly autocorrelated.

\section{Conclusion}

In this paper a dynamic model of monopolistic competition with entry and exit has been presented and examined. The number of existing firms in the intermediate sector is determined by a zero profit condition given fixed overhead costs to operate the firm. It is shown that the model displays indeterminacy at modest degrees of increasing returns in cases where the market power in the consumption goods market and in the investment goods market differs. Furthermore, the model is quite successful in replicating major U.S. business cycle facts. In contrast to existing Real Business Cycle models, the animal spirits model contains a strong endogenous propagation mechanism. 
Indeterminacy, Business Cycles and Modest Increasing Returns to Scale 25

\section{Appendix}

\subsection{The measure of returns to scale}

Suppose that the production function of a firm is given by ${ }^{14}$

$$
Y_{t}=F\left(K_{t}, L_{t}\right)-\Gamma
$$

$\Gamma$ denotes overhead costs. $F$ is homogenous of degree $\gamma$. Following the assumption that is made in the text, the functional form of $F\left(K_{t}, L_{t}\right)$ is Cobb-Douglas with $F\left(K_{t}, L_{t}\right)=K_{t}^{\alpha \gamma} L_{t}^{(1-\alpha) \gamma}$. Profits for the firm are given by

$$
\Pi_{t}=p_{t} Y_{t}-w_{t} L_{t}-q_{t} K_{t} .
$$

Denote the mark up over marginal costs by $\mu_{t}$, then the last equation implies that

$$
\Pi_{t}=p_{t} Y_{t}-\frac{\gamma}{\mu_{t}} p_{t} F\left(K_{t}, L_{t}\right)
$$

holds. ${ }^{15}$ It is assumed in the text that profits are forced to zero by market entry and exit. This yields

$$
0=Y_{t}-\frac{\gamma}{\mu_{t}}\left(Y_{t}+\Gamma\right)
$$

and

$$
Y_{t}\left(\frac{\mu_{t}}{\gamma}-1\right)=\Gamma
$$

\footnotetext{
${ }^{14}$ All variables have the same definition as in the main text unless otherwise noted.

${ }^{15}$ This equation uses the fact that

$$
\mu_{t} w_{t}=p_{t} F_{L}\left(K_{t}, L_{t}\right)
$$
}

and

$$
\mu_{t} q_{t}=p_{t} F_{K}\left(K_{t}, L_{t}\right)
$$


Indeterminacy, Business Cycles and Modest Increasing Returns to Scale 26

which restricts $\mu_{t} \geq \gamma$. A useful measure of returns to scale is the ratio of average to marginal costs (see for example Takayama, 1994). Denote returns to scale by $\Phi$. Profit maximization implies (together with Cobb-Douglas technology)

$$
\Phi=\frac{A q_{t}^{\alpha} w_{t}^{1-\alpha}\left(Y_{t}+\Gamma\right)^{\frac{1}{\gamma}}}{Y_{t}} \frac{\gamma}{A q_{t}^{\alpha} w_{t}^{1-\alpha}\left(Y_{t}+\Gamma\right)^{\frac{1}{\gamma}-1}}=\gamma \frac{Y_{t}+\Gamma}{Y_{t}}
$$

where $A$ is a constant. ${ }^{16}$ Using (37) the last equation reduces to $\Phi=\mu_{t}$. Therefore, increasing returns are, given the assumptions made in the text, equal to the markup. ${ }^{17}$

This can be interpreted as follows: assume that $\mu_{t} \rightarrow 1$. This means that the market structure approaches perfect competition. Average costs equal marginal costs and the firm produces at minimum average cost. This situation cannot be consistent with positive overhead, however. As $\mu$ rises, firms gain market power over their product. Using the zero profit condition the size of each firm's output (with zero profits) can be determined. In addition, each firm now produces with increasing returns to scale. It is implicit in equation (38) that the measure of increasing returns to scale is exactly equal to the mark up. The measure is independent of the degree of homogeneity of $F$ (and therefore $\gamma$ ). $\gamma$ determines the slope of the marginal costs schedule only.

\footnotetext{
${ }^{16}$ Reminder: the cost function is given by $A q_{t}^{\alpha} w_{t}^{1-\alpha}\left(Y_{t}+\Gamma\right)^{\frac{1}{\gamma}}$.

${ }^{17}$ Note that this measure of returns to scale is not dependent on entry and exit of firms per se. Actually, this local measure would be the same if one would assume that profits average to zero as in Hornstein (1993) (combined with a constant number of firms).
} 
Indeterminacy, Business Cycles and Modest Increasing Returns to Scale 27

\section{References}

[1] Audretsch, David B. and Z. J. Acs (1991): "New-Firm Startups, Technology and Macroeconomic Fluctuations", WZB, Discussion Paper, \# 91-17.

[2] Azariadis, Costas (1992): "The Problem of Multiple Equilibrium", UCLA, mimeo.

[3] Basu, Susanto (1996): "Procyclical Productivity: Increasing Returns or Cyclical Utilization?", Quarterly Journal of Economics, 111, 719-751.

[4] Basu, Susanto and John G. Fernald (1996): "Returns to Scale in U.S. Production: Estimates and Implications", Board of Governors of the Federal Reserve System, International Finance Discussion Papers \# 546.

[5] Basu, Susanto and John G. Fernald (1994): "Constant Returns and Small Markups in U.S. Manufacturing", Board of Governors of the Federal Reserve System, International Finance Discussion Papers \# 483.

[6] Baxter, Mariannne and Robert G. King (1991): "Productive Externalities and Business Cycles", Institute for Empirical Macroecomics, Federal Reserve Bank of Minneapolis Discussion Paper \# 53.

[7] Benhabib, Jess and Roger E. A. Farmer (1994): "Indeterminacy, and Increasing Returns", Journal of Economic Theory, 63, 19-41.

[8] Benhabib, Jess and Roger E. A. Farmer (1996): "Indeterminacy, and Sector Specific Externalities", Journal of Monetary Economics, 37, 421-443.

[9] Benhabib, Jess and Roger E. A. Farmer (1997): "Indeterminacy and Sunspots in Macroeconomics", UCLA, Department of Economics, mimeo.

[10] Burnside, Craig, Martin Eichenbaum and Sergio Rebelo (1995): "Capital Utilization and Returns to Scale", NBER Macroeconmics Annual, 10, 67-110.

[11] Cechetti, Stephen G., Pok-Sang Lam and Nelson C. Mark (1993): "The Equity Premium and the Risk-Free Rate: Matching the Moments", Journal of Monetary Economics, 31, 21-45.

[12] Chatterjee, Satyajit and Russel W. Cooper (1993): "Entry and Exit, Product Variety and the Business Cycle", Boston University, Department of Economics, mimeo.

[13] Cogley, Timothy and James M. Nason (1995): "Output Dynamics in Real Business Cycle Models", American Economic Review, 85, 492-511.

[14] Devereux, Michael C., Allen C. Head and Beverly J. Lapham (1996): "Monopolistic Competition, Increasing Returns and the Effects of Government Spending", Journal of Money, Credit, and Banking, 233-254.

[15] Farmer, Roger E. A. and Jang Ting Guo (1994): "Real Business Cycles and the Animal Spirits Hypothesis", Journal of Economic Theory, 63, 42-72. 
Indeterminacy, Business Cycles and Modest Increasing Returns to Scale 28

[16] Gali, Jordi (1994): "Monopolistic Competition, Business Cycles and the Composition of Aggregate Demand", Journal of Economic Theory, 63, 73-96.

[17] Hansen, Gary D. (1985): "Indivisible Labor and the Business Cycle", Journal of Monetary Economics, 16, 309-328.

[18] Hornstein, Andreas (1993): "Monopolistic Competition, Increasing Returns to Scale, and the Importance of Productivity Shocks", Journal of Monetary Economics, 31, 299-316.

[19] King, Robert G., Charles I. Plosser and Sergio T. Rebelo (1988): "Production, Growth and Business Cycles I: The Basic Neoclassical Model", Journal of Monetary Economics, 31, 195-232.

[20] McGrattan, Ellen R. (1994): "A Progress Report on Business Cycle Models", Federal Reserve Bank of Minneapolis Quarterly Review, 18, 2-16.

[21] Morrison, Catherine (1990): "Market Power, Economic Profitability and Productivity Growth Measurement: An Integrated Structual Approach", NBER Working Paper \# 3355 .

[22] Rogerson, Richard (1987): "Indivisible Labor, Lotteries and Equilibrium”, Journal of Monetary Economics, 21, 3-16.

[23] Schmitt-Grohe, Stephanie (1995): "Comparing Four Models of Aggregate Fluctuations Due to Self-Fulfilling Expectations", Federal Reserve Board Finance and Economics Discussion Papers \# 95-17, and Journal of Economic Theory, (forthcoming).

[24] Shea, John (1993): "Do Supply Curves Slope Up?", Quarterly Journal of Economics, $108,1-32$.

[25] Takayama, Akira (1994): Analytical Methods in Economics, Harvester Wheatsheaf, New York.

[26] Weder, Mark (1996): "Animal Spirits, Technology Shocks and the Business Cycle", Humboldt University Berlin, Department of Economics, mimeo. 